\title{
Circadian rhythm and sleep influences on digestive physiology and disorders
}

This article was published in the following Dove Press journal:

ChronoPhysiology and Therapy

2 September 2014

Number of times this article has been viewed

\author{
Bradley V Vaughn \\ Sean Rotolo \\ Heidi L Roth \\ Division of Sleep Medicine, \\ Department of Neurology, \\ University of North Carolina \\ School of Medicine, Chapel Hill, \\ NC, USA
}

Correspondence: Bradley V Vaughn Division of Sleep Medicine, Department of Neurology, University of North Carolina School of Medicine, Physicians Office Building, 170 Manning Drive, Chapel Hill, NC 27599, USA

Email vaughnb@neurology.unc.edu

\begin{abstract}
Circadian rhythms and sleep influence a variety of physiological functions, including the digestive system. The digestive system also has intrinsic rhythms that interact dynamically with circadian rhythms. New advances in understanding the interaction of these rhythms and sleep provide the prospect of evaluating their role in normal physiology and the link of their disruption to pathological conditions. Recent work has demonstrated that sleep and circadian factors influence appetite, nutrient absorption, and metabolism. Disruption of sleep and circadian rhythms may increase vulnerability to digestive disorders, including reflux, ulcers, inflammatory bowel issues, irritable bowel disease, and gastrointestinal cancer. As our knowledge of the link between circadian timing and gastrointestinal physiology grows, so do our opportunities to provide promising diagnostic and therapeutic approaches for gastrointestinal disorders.
\end{abstract}

Keywords: digestion, digestive diseases, gastrointestinal reflux, sleep, circadian rhythm

\section{Introduction}

Circadian rhythms and sleep influence the physiology of nearly every organ system, including the digestive tract. In addition, these drivers shape the brain's control over the autonomic and endocrine system throughout the 24-hour cycle. The dynamic bidirectional relationship between the brain and gastrointestinal (GI) system includes feedback loops to the circadian and sleep-regulation pathways. Although sleep triggers several changes in the digestive system, the GI tract demonstrates its own circadian and ultradian rhythms. In this review, we use the foundation of normal physiology to review recent work demonstrating the interaction of circadian influences on GI disorders.

\section{Normal physiology}

The circadian rhythm serves to prepare the body for anticipated events, such as feeding and activity. As the master clock, the suprachiasmatic nucleus is responsible for coordinating and synchronizing the circadian rhythm throughout the body. The suprachiasmatic nucleus, like many organs, utilizes a multilooped feedback system of genetic transcription and a nuclear and cellular protein system that oscillates at approximately 24 hours. ${ }^{1}$ Even though $7 \%-12 \%$ of genes fluctuate in a circadian fashion, the essence of this clock resides in the genetic transcription of the CLOCK and BMAL1 genes. Once transcribed, these form a protein heterodimer that binds and activates E-box sequence promoters that positively influence the transcription of PER1, PER2, $P E R 3, C R Y 1$, and $C R Y 2$. The protein products of the $P E R$ and $C R Y$ genes dimerize and feedback negatively on the transcription of the CLOCK and BMAL1 genes, creating 
the circadian rhythm. This rhythm is not exactly 24 hours, and thus the clock must be adjusted by environmental time clues. The most powerful time clue is bright light, but food also appears to influence the phase of the biological clock. The suprachiasmatic nucleus synchronizes the peripheral circadian rhythm clocks by utilizing melatonin, in addition to the endocrine and autonomic nervous system outputs.

In addition to the circadian rhythm, the sleep state also influences GI physiology. As an active process of the brain, sleep is physiologically distinct from wakefulness. The states of rapid eye movement (REM) sleep and non-REM (NREM) sleep use distinct complex neuronal networks involving hypothalamic, diencephalic, and brain-stem nuclei to affect the remaining central nervous system. ${ }^{2}$ As a consequence of this, the output of the brain neurohumoral system is different depending upon the sleep state. NREM sleep is typically viewed as a time of greater parasympathetic output to the body, whereas REM sleep is associated with surges of sympathetic and parasympathetic activity.

Sleep is normally paired with decreased circadian drive for wakefulness, but these are distinct processes with different influences. Some regulatory functions may be affected by sleep stage, while others exhibit circadian patterns. This distinction between circadian rhythm and sleep stage may seem academic, but it is crucial when determining underlying root causes of physiological effects or in postulating therapies. Sleep-dependent functions may be improved by adjustment of factors that influence sleep, whereas circadian rhythm-related issues may respond better to alignment of circadian time givers. Our current literature is limited by few studies that separate the two, but we highlight what evidence exists and discuss key points of distinction (Table 1).

\section{Feeding and circadian rhythm}

Meals have distinct cultural and endogenous timing. Food appears to entrain specific circadian rhythm oscillators. These entrainable oscillators appear to play a role in anticipating

Table I Circadian and sleep influence on digestive function

\begin{tabular}{lll}
\hline Digestive function & $\begin{array}{l}\text { Circadian } \\
\text { influence }\end{array}$ & $\begin{array}{l}\text { Sleep-stage } \\
\text { influence }\end{array}$ \\
\hline Saliva production & Possibly pH & Yes \\
Swallows/esophageal motility & No & Yes \\
Gastric acid secretion & Yes & Unclear \\
Gastric motility & Unclear & Yes \\
Intestinal absorption & Yes & Unclear \\
Intestinal motility & Potentially & Yes \\
Colonic motility & Potentially & Yes \\
Rectum/anal function & Potentially & Yes \\
\hline
\end{tabular}

food intake and enhance eating behavior. ${ }^{3}$ Many hormones oscillate in a daily fashion to anticipate feeding, including ghrelin, leptin, corticosterone, insulin, glucagon, and glucagon-like peptide 1 , but the exact role of these compounds is unclear. ${ }^{4}$ These food-related oscillators are poorly localized, but a significant portion reside in the stomach. A major part of this clock is comprised of oxyntic gland cells that release ghrelin, Per1, and Per2 in a rhythmic fashion. ${ }^{5}$ Unlike a true circadian rhythm that continues without time clues, this rhythm is related to the availability of food, but is abolished in constant darkness and with ad lib food routine. The absence of Per1 and Per2 also appears to remove the rhythmic release of ghrelin, but ghrelin appears to have a direct effect on the suprachiasmatic nucleus, suggesting the interplay of the food oscillators and the circadian rhythm. ${ }^{6}$ Ghrelin and leptin also directly feedback on the hypothalamus, and may play an additional role in the feeding cycle utilizing orexin and melanocortin. ${ }^{4}$

Disruption of any circadian rhythm is more easily identified by a change in phase or the loss of the identified rhythm. Circadian rhythm disorders with changes in phase are classically divided into either the advanced- or delayed-phase type. An example of a circadian disorder with loss of rhythm is circadian rhythm disorder, irregular type. Disruption of the feeding-entrainment clock has been implicated in two disorders: nocturnal eating syndrome and shift work. In nocturnal eating syndrome, evidence suggests the inherent feeding rhythm is delayed so that the major feeding period is late in the typical day. ${ }^{7}$ Many of these patients also have features of delayed sleep phase, but note they are not hungry until late evening and have anorexia in the morning. Disruption of the feeding oscillators also has been linked to obesity and metabolic disruption in shift work, and may have further implications for feeding habits. Part of the evidence for this resides in the higher rates of obesity and metabolic disruption that are seen in individuals working shift work. ${ }^{8}$ Experimentally, mice given ad lib food access to a high-fat diet abolished their circadian rhythm for feeding, gained weight, and had more metabolic disruption than mice given the same number of calories from a timed high-fat diet. This suggests the circadian rhythm plays an important role in the regulation of metabolic processing of food. ${ }^{9}$ This finding may have implications for shift work, but may be in addition to the role shorter sleep and sleep disruption may play in weight gain and metabolic disruption. Similar work by Spiegel et al shows that sleep deprivation by itself influences caloric intake, glucose utilization, and leptin resistance. ${ }^{10}$ 


\section{Initial digestion}

Digestion begins in the mouth as the process of chewing, salivation, and swallowing. These initial digestive processes are linked to the waking state, but to date little information is known regarding their circadian links. Although chewing obviously declines in sleep, salivary production dramatically declines from $0.5 \mathrm{~mL} /$ minute to near zero in sleep. ${ }^{11,12}$ Salivary $\mathrm{pH}$ also lowers during the night. Investigators suggest circadian influence lowers $\mathrm{pH}$ during the night, but this work has not desynchronized the sleep cycle from the circadian cycle to determine the driver of this change. ${ }^{13}$ Similarly, swallowing rates decrease from approximately 25 times per hour during wakefulness to approximately five times per hour during sleep and usually follow arousals. Despite decreased swallowing during sleep, the airway is protected by the cricopharyngeal muscle, which provides the pressure barrier to the proximal esophagus to inhibit aspiration. This muscle is unique in that unlike most skeletal muscles during REM sleep, it retains tone throughout all sleep stages. ${ }^{14}$ Swallows also must overcome the cricopharyngeal muscle and upper esophageal sphincter pressure to allow the food bolus to enter the esophagus. Although the former retains contraction, the latter decreases closing pressures during deep sleep to levels less than $25 \%$ of that in waking.

Swallows initiate most esophageal primary peristalsis, and these decrease progressively with deeper NREM sleep and REM sleep. Secondary peristalsis unrelated to swallows also declines in NREM sleep, but increases in REM sleep related to central autonomic nervous system output or decrease in some inhibitory processes. ${ }^{15,16}$ Using continuous manometry without sleep measures or forced desynchronization of sleep from circadian cycles, Stein et al found a decrease in esophageal contractions during the night. Although they suggested a circadian component, the link will need further study to determine if this is related to sleep or the circadian rhythm. ${ }^{17}$ The lower esophageal sphincter (LES) also decreases tone during sleep, but typically stays above that of intragastric pressure. Dent et al found that 5- to 30-second drops in LES pressure paired with sudden increases in intra-abdominal pressure in sleep resulted in gastric reflux. ${ }^{18}$ Therefore, during sleep the esophagus becomes more vulnerable to gastric acid by the lower rate of swallows, decreased salivary volume, and less peristalsis leading to increased gastric acid-mucosal contact time.

\section{Gastroesophageal reflux disease}

Gastroesophageal reflux disease is influenced by both circadian and sleep factors, which make nocturnal reflux distinct from diurnal reflux. ${ }^{19}$ Circadian rhythm and sleep state influence esophageal reflux primarily by diminishing the defenses against reflux events. Reflux events that occur during sleep, compared to events in wakefulness, are less frequent, but have significantly longer contact times due to reduced esophageal clearance. This reduced clearance and increased potential for mucosal damage is due to sleep factors of diminished saliva production (especially bicarbonate), decreased swallowing rate, decreased LES pressure, and decreased arousal responses, and circadian-dependent factors, including increased gastric acid production and delayed gastric emptying. The loss of esophageal protective mechanisms and greater acid exposure with reflux events is correlated with the occurrence of esophagitis and risk of mucosal damage. ${ }^{20}$ Interestingly, disrupted sleep has also been shown to lead to more reflux noted on $\mathrm{pH}$ recording on the following night. ${ }^{21}$

\section{Stomach}

The major roles of the stomach include acidification of ingested food and control of flow of the food bolus into the duodenum. Acid secretion helps to control the introduction of organisms into the digestive tract and denatures some proteins for easier digestion. The controlled flow of food to the small intestine may help optimize nutrient absorption. Sleep and circadian rhythm may influence acid secretion and gastric motor activity. Acid secretion is highly variable from night to night, yet peaks in a circadian fashion between $10 \mathrm{pm}$ and 2 am, suggesting a circadian component (Figure 1). ${ }^{22}$ This peak is not seen in patients who have undergone vagotomy, signifying a direct parasympathetic influence. ${ }^{23}$ However, the influence of sleep is more debated. Although Stacher et al found REM sleep was associated with inhibition of acid secretion, Watanabe et al reported that when comparing gastric $\mathrm{pH}$ to waking, levels were higher in NREM and even more elevated in REM sleep. ${ }^{24,25}$ Despite the technical and power limitations of these studies, overall they suggest that the central nervous system influences acid secretion through the circadian rhythm and potentially through sleep mechanisms. Interestingly, investigators found patients with duodenal ulcers lost these rhythms of acid secretion. ${ }^{24}$

Original investigation into the pathogenesis of duodenal ulcers showed a constant overproduction of acid throughout the day and night. This loss of acid-secretion rhythm was postulated as part of the reason for ulcer formation. Linkage of this overproduction is related to chronic Helicobacter pylori infection. This organism causes a reduction in somatostatin levels, which in turn allows for the increase in parietal 


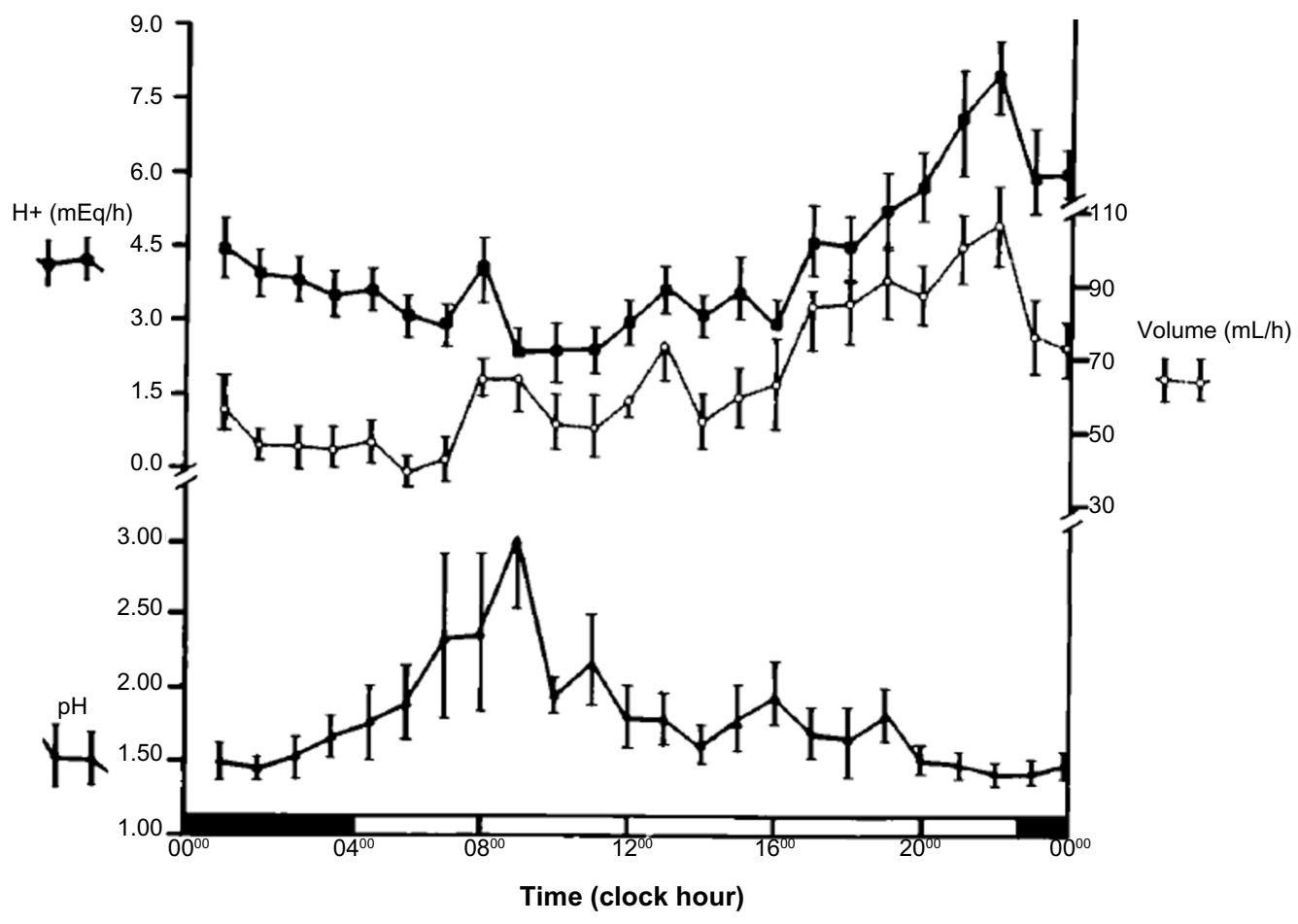

Figure I The circadian pattern of gastric acid secretion across a 24-hour period.

Notes: The relationship between basal acid secretion (total $\mathrm{H}=$ in $\mathrm{Eq} / \mathrm{h}$ ), volume $(\mathrm{mL} / \mathrm{h}$ ), and gastric $\mathrm{pH}$ is shown for a group of healthy male subjects. Note the peak acid secretion is just before midnight. Copyright (c) 2006, John Wiley and Sons. Reproduced from: Moore JG. Circadian dynamics of gastric acid secretion and pharmacodynamics of $\mathrm{H} 2$ receptor blockade. Ann NY Acad Sci. 1991;618:150-158.22

Abbreviations: $\mathrm{H}+$, acid secretion; $h$, hour; $\mathrm{mEq}$, milliequivalent.

cell mass and overproduction of acid without a circadian pattern. ${ }^{26}$ For these patients, the loss of the circadian variation in acid secretion never allows full recovery of the duodenal mucosa. Treatment of these ulcers is more successful if antibiotics are used with a proton-pump inhibitor to decrease acid secretion and reestablish a mucosal recovery period. ${ }^{27,28}$ Similar to gastric acid-related rhythm, the circadian rhythm also regulates the rhythmic secretion of trefoil protein. This protein helps protect the gastric mucosa from damage. $H$. pylori infection similarly interferes with trefoil protein release, increasing the risk of mucosal damage. ${ }^{29}$ Trefoil protein release is also reduced by sleep deprivation, indicating a linkage to both circadian and sleep-related processes. These ulcers may also be more likely to heal with melatonin administration. ${ }^{30}$

Melatonin may improve mucosal regeneration as a downstream circadian influence. As a hormone released in response to a dark environment, melatonin is released by some gut cells in a circadian fashion as well. This hormone is produced by neuroendocrine cells of the stomach and duodenal mucosa, and helps keep the clock synchronized, including food intake and myoelectric rhythm. This rhythm improves mucosal healing in a circadian pattern. Melatonin appears to inhibit gastric acid release, increase gastric blood flow, and improve mucosal regeneration. In individuals with lower melatonin release, gastric stress ulcers take longer to heal. Exogenous melatonin appears to improve mucosal healing in these individuals. This may be related to the antioxidant features of melatonin, but further investigation is needed..$^{30}$ Melatonin also has an effect on mucosal development and villus height, total mucosal thickness, and cell mitosis. ${ }^{31}$

Motor control of the stomach is divided by region and type of food bolus. The fundus of the stomach controls primarily liquid food, while the antrum controls solids. While each of these use different mechanisms to regulate flow, gastric contents must flow into the duodenum for further digestion. Gastric motor function is controlled by the innate gastric pacemaker, an electrical generator from smooth muscle in the proximal greater curvature of the stomach. The gastric cycle typically occurs two to four times/minute, moving the food bolus toward the duodenum. Similar to acid secretion, early findings for the relationship of gastric contractions and sleep stage showed contradictory effects. ${ }^{32}$ Although this activity is traditionally thought to be independent of central nervous system activity, more sophisticated electrical recording demonstrates that the amplitude of the gastric cycle declines 
Table 2 Various roles of melatonin in gastrointestinal $(\mathrm{Gl})$ disorders

\begin{tabular}{|c|c|c|c|}
\hline Role & Mechanism & GI disorder & Reference(s) \\
\hline $\begin{array}{l}\text { Improves mucosal regeneration via } \\
\text { downstream circadian influence }\end{array}$ & $\begin{array}{l}\text { Produced by neuroendocrine cells of stomach and duodenal } \\
\text { mucosa; inhibits gastric acid release, increases gastric blood flow }\end{array}$ & Ulcers & 30 \\
\hline Improves mucosal regeneration & Improves villus height, total mucosal thickness, and cell mitosis & Ulcers & 31 \\
\hline Measure of circadian rhythm function & & IBS and others & 70,71 \\
\hline Anticarcinogenic & Unclear & Gl cancers & $78-81$ \\
\hline In development or control of IBD & $\begin{array}{l}\text { Proposed: synchronization of gut circadian rhythms, direct } \\
\text { modification of intestinal permeability, antioxidant effects, } \\
\text { change in blood flow, improvement in mucosal repair, or } \\
\text { immunoregulatory function }\end{array}$ & IBD & 93 \\
\hline $\begin{array}{l}\text { Slow GI motility and smooth- } \\
\text { muscle cell contraction }\end{array}$ & $\begin{array}{l}\text { Interaction with serotonin receptors present on the vagal } \\
\text { afferent fibers and inducing vagovagal inhibitory reflexes }\end{array}$ & IBS and others & 94 \\
\hline $\begin{array}{l}\text { Prevention of dextran sodium } \\
\text { sulfate-induced colitis }\end{array}$ & $\begin{array}{l}\text { Prevents development of colitis when given as pretreatment, } \\
\text { mechanism unclear }\end{array}$ & Colitis & 95 \\
\hline
\end{tabular}

Abbreviations: IBS, irritable bowel syndrome; IBD, inflammatory bowel disease.

in NREM sleep and returns in REM sleep. ${ }^{33,34}$ Some of this activity may be circadian in nature, as evidenced by slower emptying in the evening wake state..$^{35}$

The small intestine is principally responsible for the absorption of nutrients and propagation of the food bolus toward the colon. Although the area of nutrient absorption in sleep is largely unstudied, Soffer et al found no change in intestinal absorption with sleep. ${ }^{36}$ Intestinal motility, as manifested by the migrating motor complex (MMC), starts as an intermittent contraction in the stomach and migrates to the colon. Several authors have found a decrease in MMC velocity that may be partially regained by a late-evening meal. ${ }^{37,38}$ Sleep-related MMC duration is also longer with the early follicular phase of the menstrual cycle, and early evening alcohol may increase the contraction amplitude of the jejunum during sleep. ${ }^{39,40}$ Soffer et al also found that food-induced secretion of gastrin, neurotensin, peptide YY, and pancreatic polypeptides were not influenced by sleep, despite decreased MMC. ${ }^{36}$ Looking at other excretory functions, Keller et al found an increase in amylase output and no change in protease output during sleep. ${ }^{41}$ These studies suggest that sleep-related effects on intestinal motility may be altered by nondigestive endocrine and other neural influences, but the effect of the circadian rhythm is unclear.

The circadian rhythm may influence nutrient absorption. ${ }^{42}$ Early work showed that peak histidine and glucose absorption in rats occurred during their active period. Although this originally may have been related to activity level, further work showed that the levels of intestinal ion, glucose, and peptide transporters have a circadian oscillation. ${ }^{42-45}$ PEPT1 peaks just prior to their active phase when rats start their food intake. These transporters showed oscillation even during the fasting state. Although messenger ribonucleic acid cycling appears uninfluenced by neural input, the diurnal protein expression of PEPT1 is partially influenced by vagal output. ${ }^{46}$ However, jejunal isolates obtained from rats at different points of the circadian cycle showed continued cycling of sodium-glucose cotransporter $1 .{ }^{47}$ Similarly, lipid absorption appears also to have some circadian rhythmicity through protein expression, but the mechanism is not understood. ${ }^{48}$

The clinical significance of these transporters is their presence in anticipation of the food bolus, which allows for optimal absorption of nutrients. Although disruption of these rhythms of absorption proteins has not been directly linked to pathological states, their disruption may be manifested in features of malabsorption or nutritional deficiencies. Yet the gut has a significant reserve to compensate even after resection of large sections of the bowel. This reserve capacity may mute clinical expression of any disorder. Some clue may come from vulnerable populations that show absorption issues. In some individuals with short-bowel syndrome, nocturnal enteral feeding is better tolerated as a long-term strategy. Similarly, cervical cancer patients undergoing radiation therapy in the morning were much more likely to develop diarrhea and intestinal mucositis than those receiving radiation therapy in the evening. ${ }^{49}$ This may be more related to repair of the intestinal lining than the issue of absorption, but it shows a vulnerability to timing and absorption. In the same way, circadian rhythm disruption of both large and small intestines has been implicated in patients with irritable bowel syndrome (IBS). ${ }^{50}$ Nutritional deficiencies also may have been postulated as a potential manifestation of disruption of intestinal circadian rhythm issues. ${ }^{51,52}$ This may have bidirectional implications, since nutritional deficiencies may also influence specific portions of expression of the circadian rhythm. 


\section{Large colon}

The human colon has two principal functions: water absorption and temporary containment of intestinal material. Colonic motor function is a complex noncyclic event mostly independent of the more minor motor contractions that must move feces caudally. ${ }^{53}$ The functions opposing fecal material moving caudally maintain continence by utilizing coordinated motoric events to accomplish this goal. Most colonic motility decreases in sleep, but the circadian influence may still be a factor yet to be identified ${ }^{54}$ Colonic contractions that propagate material caudally are significantly reduced during the night, and are nearly eliminated during slow-wave sleep. However, REM sleep was associated with increased colonic pressure and frequency of propagating contractions to levels similar to stage 2 sleep. ${ }^{55}$ Similar to wakefulness, transient arousals stimulate a significant increase in propagating contractions in all segments of the colon. ${ }^{55-57}$ To maintain fecal continence during sleep, rectal motor and anal sphincters utilize the complex cyclic rectal motor activity. This cyclic rectal motor activity stops the forward propagation of colonic waves at night, producing more retrograde propagation of the contracting wave. ${ }^{58}$ This activity in sleep is typically independent of anal activity and counteracts forward propagating colonic activity. Also during sleep, the internal anal sphincter retains active pressure independently of external sphincter activity, suggesting that the two are controlled by separate processes. ${ }^{59,60}$ More importantly, anal canal pressure remains above rectal pressure to maintain continence in sleep. ${ }^{61}$

\section{Irritable bowel syndrome}

Dysfunction of the sleep-wake control or circadian clocks of the small and large intestine has been implicated in IBS. This disorder is a constellation of symptoms, including alternating constipation and diarrhea, that affects approximately $8 \%-23 \%$ of the population in the Western world. ${ }^{62}$ Although the exact pathophysiology of this disorder is unclear, the brain-gut bidirectional connections, including emotional and cognitive factors, have been used to explain its basis. ${ }^{63}$

IBS may also be at least partially explained by sleep state. One hypothesis for the cause of IBS postulates disruption of the sleep state-dependent autonomic control of intestinal function. At least two studies have demonstrated that IBS patients have greater overall sympathetic activity during REM sleep, but another study showed no difference between women with IBS and normal controls. ${ }^{64-66}$ Some of this confusion may be related to mixing of IBS-subgroup types, obscuring significant differences in markers of autonomic activity between the subgroups and the normal population. Jarrett et $a l^{65}$ showed that women with diarrhea-predominant IBS demonstrated significantly increased parasympathetic activity across both NREM and REM cycles compared to constipation-predominant and alternating IBS subjects. In contrast, Robert et $\mathrm{al}^{66}$ showed that diarrhea-predominant patients showed physiologically distinct autonomic activity during sleep compared to patients with alternating patterns, but not patients with constipation predominance. ${ }^{67}$ Therefore, further investigation may show that sleep dependent physiology may offer further clues into the underlying pathophysiology. Furthermore, these autonomic clues may also impart some inference to the potential influence of the circadian control.

The circadian influence in IBS may be related to the circadian disruption of small-intestine motor activity seen in individuals with IBS. In a study of constipation-predominant and diarrhea-predominant IBS patients, continuous 72-hour recordings of duodenojejunal contractile activity were obtained from freely ambulant subjects. This revealed diurnal differences, with daytime postprandial motor activity being shorter in IBS patients than controls, and diurnal MMC intervals being shorter in diarrhea-predominant than in constipation-predominant IBS. ${ }^{68}$ Interestingly, there was no difference in patterns of motor activity during sleep between any of the groups. This disruption in diurnal motor activity may explain differences in IBS defecation patterns and pain.

Circadian influence can also be inferred by studies on shift workers without previously known IBS. One cohort study surveying Korean shift workers (nurses and nursing assistants) found that the prevalence of IBS was significantly higher in the rotating shift-worker group compared to the daytime-worker group (32.7\% versus $16.7 \%, P=0.026){ }^{67}$ Logistic regression analysis found an association between IBS and rotating shift work even after controlling for other confounding factors, such as poor sleep quality. In another cross-sectional study involving US nurses working day, night, or rotating shifts, there was a significantly higher prevalence of symptoms of IBS and abdominal pain in the group rotating their shifts compared to the other two, even after controlling for sleep quality. ${ }^{69-70}$ Both studies raised the issue that more abdominal pain was noted in the groups with rotating shifts, and this could be due to disruption of circadian factors that modulate visceral sensitivity. When IBS subtypes were assessed, the rotating shift schedule did not predict such a robust difference when compared to the other two shift types. In a small study of healthy young male volunteers 
using stepwise increases in rectal balloon distention, minimal perception did not vary over the course of 20 hours. However, a lower threshold was found at the initial time point (6 pm) and then at $6 \mathrm{am}$. This increase in pain perception may be related to diurnal factors. For the 6 am time point, sleep deprivation could also be a factor, since subjects were given only 4.5 hours to sleep (between 1 and 5.30 am). ${ }^{70}$

One measure of circadian rhythm function is the release of melatonin. As noted earlier, melatonin has many effects on the GI system (Table 2). When measured in individuals with IBS, one set of investigators found lower urinary metabolites of melatonin, while another found normal metabolite levels. ${ }^{71,72}$ Further investigation utilizing melatonin supplementation showed that melatonin may improve the symptoms of IBS, and that these improvements could not be accounted for by change in sleep or antioxidant measures. ${ }^{73}$ In a review of four double-blind placebo-controlled trials, three of the four trials showed improvement in IBS symptoms and pain using melatonin $3 \mathrm{mg}$ every evening. ${ }^{73}$ These results suggest that melatonin may help in multiple domains, but are not conclusive in tying the circadian rhythm to IBS.

\section{Gastrointestinal cancer}

The role of circadian physiology in cancers has been widely reported, mostly in relation to breast cancer, with most studies focused on shift workers. ${ }^{74}$ This has led to the exploration of shift work's relationship with other cancers, including GI cancers. Several putative mechanisms have been proposed for explaining the relationship of shift work to cancer. Most hypotheses have focused on the effects of increased light exposure and suppression of normal secretion of melatonin. Lower melatonin levels and disruption of the circadian rhythm may affect the risk of cancer through a number of direct and indirect pathways (Table 2). ${ }^{75}$ Studies looking at the relationship between shift work and colon cancer have produced conflicting results. One study exploring the effect of night-shift work and the risk of colorectal cancer, looking prospectively at female participants in the Nurses' Health Study, found a significantly increased relative risk of 1.35 for colon cancer in those that worked a rotating night shift at least 3 nights per month for 15 or more years. However, three other studies looking at the risk of colon cancer in shift workers or individuals with nocturnal light exposure were unable to demonstrate a link. ${ }^{76-78}$ In vitro studies have shown anticarcinogenic properties of melatonin in chemically induced colon cancers in rodents. ${ }^{79-82}$ Melatonin is thought to act as a free radical scavenger, and thus might thereby prevent toxic damage involved in carcinogenesis or limit toxic factors that potentiate cancer growth. Other effects of melatonin include reduction of gut permeability, which might also limit gut injury. Clock genes may also have an important role in gastrointestinal cancers. As mentioned earlier, the molecular clock mechanism is based on interactions between transcription- and translation-based positive- and negative-feedback loops, regulated by the transcriptional factors CLOCK and BMAL1 and the PER and CRY genes. The CLOCK/BMAL1 heterodimer activates the transcription of other clock-controlled genes, including apoptotic and cell-cycle genes. Disruption of circadian homeostasis by mutations in certain clock components results in alterations in cell proliferation, apoptosis, deoxyribonucleic acid damage, and metabolism that in some cases predispose to cancer. ${ }^{83}$ Therefore, one hypothesis is that the circadian clock may act to time cellular division and maturation, as well as act as a tumor suppressor. Therefore, loss of response to the clock mechanism may be associated with tumorigenic growth. In a study of chemically induced colon cancer in mice, amplitudes of circadian rhythmicity in the expression of Per1, Per2, and Rev-Erbo were markedly reduced in neoplastic tissue. The rhythm of BMAL1 expression, a crucial clock-machinery component, was completely abolished in the tumors and surrounding tissue. ${ }^{84}$

There may be a metabolic link between core circadian clock machinery and suppression of intestinal tumors. The histone deacetylase SIRT1 is a crucial modulator of clock machinery, operating as a rheostat and modulating the amplitude and "tightness" of CLOCK-mediated acetylation and consequent transcription cycles in metabolic tissues. ${ }^{84,85}$ In a $\beta$-catenin-driven mouse model of colon cancer, there was significant reduction in tumor formation, proliferation, and animal morbidity with increased SIRT1 expression. ${ }^{85}$

Given the link between circadian rhythmicity and cancer, chronomodulated chemotherapy has emerged as a treatment alternative to conventional chemotherapy. In a meta-analysis conducted in 2010, five randomized clinical trials were reviewed to compare the efficacy and safety of chronomodulated chemotherapy with conventional chemotherapy in patients with advanced colorectal cancer. There was a significant overall survival benefit in favor of the chronomodulated chemotherapy. There was a lower incidence of grade 3/4 neutropenia, and higher incidence of asthenia and grade $3 / 4$ mucositis in the chronomodulated chemotherapy trials, though these findings did not reach statistical significance. ${ }^{86}$ Individual patients' circadian rhythms may also serve as a prognostic factor in patients with metastatic colorectal cancer. In a prospective study of 192 patients with 
metastatic colorectal cancer, actigraphy was used to analyze rest/activity cycles, with an autocorrelation coefficient at 24 hours and dichotomy index as measures of marked rest/activity rhythm. ${ }^{87}$ Survival was nearly fivefold higher for patients in the upper quartiles of rest/activity rhythm, compared to those in the lowest quartile. Global quality of life, physical functioning scores, and tumor response were all positively correlated with circadian rest/activity rhythm, but showed only weak associations with changes in white blood cell counts and cortisol levels. While the literature is still limited, the findings on the potential importance of the circadian timing of chemotherapy delivery in the treatment of GI cancer are intriguing and warrant continued investigation.

\section{Inflammatory bowel disease}

Inflammatory bowel disease (IBD) is a disorder of chronic inflammation of the small or large intestine, and is primarily identified with Crohn's disease and ulcerative colitis. IBD may be affected by sleep and circadian rhythms through complex immune-mediated pathways, since both sleep and circadian rhythm play a role in the regulation of immune function. The immune system of the gut is under circadian regulation, and inflammatory mediators, such as TNF $\alpha$, have been found to suppress clock gene expression. Additionally, circadian clock genes can impact intestinal epithelial cell permeability. Gut leakiness is considered an important mechanism for initiating the inflammatory cascades seen in patients with IBD during a disease flare. ${ }^{88}$ Animal models have demonstrated that alterations in the sleep-wake cycle stimulate the migration of immune cells (white blood cells, monocytes, and natural killer cells) into tissues and stimulate the release of proinflammatory cytokines (IL-6, IL-1, TNF $\alpha) .{ }^{89-92}$ As evidence that sleep disturbances might directly impact inflammatory processes in the colon, Tang et al showed that both acute and chronic sleep deprivation exacerbated colonic inflammation in mouse models of colitis. ${ }^{93}$ Similarly, inflammatory mediators, such as TNF $\alpha$, suppress clock gene expression. ${ }^{94}$ In a study of mice exposed to four consecutive weekly 6-hour phase advances of the light-dark schedule, then subjected to endotoxemic shock, there was $89 \%$ mortality compared with $21 \%$ in unshifted control mice. Part of the explanation for this increased mortality was exaggerated immune response with cytokine deregulation..$^{95}$ The relationship of an exaggerated immune response following circadian disruption to the inflammatory cascade of IBD has yet to be determined, but does raise interesting possibilities.
Melatonin may also have an effect on the development or control of IBD (Table 2). ${ }^{96}$ This could be through synchronization of gut circadian rhythms or by direct modification of intestinal permeability, antioxidant effects, change in blood flow, improvement in mucosal repair, or immunoregulatory function. As an important regulator of circadian rhythms, melatonin can also slow GI motility and smooth-muscle cell contraction caused by serotonin. ${ }^{97}$ In a mice model of colitis induced by dextran sodium sulfate, melatonin was found to be able to prevent dextran sodium sulfate-induced colitis and prevent its formation when given as pretreatment. ${ }^{98}$ In other murine model studies, melatonin was able to reverse both the increase in intestinal permeability and influx of bacterial endotoxins and decrease myeloperoxidase and TNF $\alpha$ activity, which leads to ulcerations. ${ }^{99,100}$ To date, only a small number of human studies have shown beneficial effects of melatonin in patients with IBD, and the mechanism by which the improvements are mediated is unclear. ${ }^{101,102}$

\section{Conclusion}

Sleep and the circadian rhythm are vitally linked to the proper functioning of the digestive system. As the roles these two physiological systems play in the regulation of the digestive system become clearer, so will the opportunities they provide for understanding GI and nutritional disorders. Further studies involving the manipulation of the circadian rhythm and sleep will also help delineate the role they may play in contributing to bowel disease and the opportunity for improvement in digestive health.

\section{Disclosure}

The authors report no conflicts of interest in this work.

\section{References}

1. Lowrey PL, Takahashi JS. Genetics of circadian rhythms in mammalian model organisms. Adv Genet. 2011;74:175-230.

2. Moszczynskia A, Murray BJ. Neurobiological aspects of sleep physiology. Neurol Clin. 2012;30:963-985.

3. Landry GJ, Mistlberger RE. Food entrainment: methodological issues. J Biol Rhythms. 2007;22:484-487.

4. Patton DF, Mistlberger RE. Circadian adaptations to meal timing: neuroendocrine mechanisms. Front Neurosci. 2013;7:185.

5. Lesauter J, Hoque N, Weintraub M, Pfaff DW, Silver R. Stomach ghrelinsecreting cell as food entrainable circadian clocks. Proc Natl Acad Sci U S A. 2009; 106:13582-13587.

6. Lamont EW, Bruton J, Blum ID, Abizaid A. Ghrelin receptor-knockout mice display alterations in circadian rhythms of activity and feeding under constant lighting conditions. Eur J Neurosci. 2014;39:207-217.

7. Milano W, De Rosa M, Milano L, Capasso A. Night eating syndrome: an overview. J Pharm Pharmacol. 2012;64:2-10.

8. Lowden A, Moreno C, Holmbäck U, Lennernäs M, Tucker P. Eating and shift work - effects on habits, metabolism and performance. Scand $J$ Work Environ Health. 2010;36:150-162. 
9. Sherman H, Genzer Y, Cohen R, Chapnik N, Madar Z, Froy O. Timed high-fat diet resets circadian metabolism and prevents obesity. FASEB J. 2012;26:3493-3502.

10. Spiegel K, Tasali E, Leproult R, Van Cauter E. Effects of poor and short sleep on glucose metabolism and obesity risk. Nat Rev Endocrinol. 2009;5:253-261.

11. Schneyer LH, Pigman W, Hanahan L, Gilmore RW. Rate of flow of human parotid, sublingual, and submaxillary secretions during sleep. $J$ Dent Res. 1956;35:109-114.

12. Lear CS, Flanagan JB Jr, Moorrees CF. The frequency of deglutition in man. Arch Oral Biol. 1965;10:83-100.

13. Watanabe M, Sano H, Tomita K, et al. A nocturnal decline of salivary $\mathrm{pH}$ associated with airway hyperresponsiveness in asthma. $J$ Med Invest. 2010;57:260-269.

14. Kahrilas PJ, Dodds WJ, Dent J, Haeberle B, Hogan WJ, Arndorfer RC. Effect of sleep, spontaneous gastroesophageal reflux, and a meal on upper esophageal sphincter pressure in normal human volunteers. Gastroenterology. 1987;92:466-471.

15. Castiglione F, Emde C, Armstrong D, et al. Nocturnal oesophageal motor activity is dependent on sleep stage. Gut. 1993;34 1653-1659.

16. Orr WC, Elsenbruch S, Harnish MJ, Johnson LF. Proximal migration of esophageal acid perfusions during waking and sleep. Am J Gastroenterol. 2000;95:37-42.

17. Stein HJ, Singh S, Demeester TR. 'Efficacy' of esophageal peristalsis a manometric parameter to quantify esophageal body dysfunction. Dis Esophagus. 2004;17:297-303.

18. Dent J, Dodds WJ, Friedman RH, et al. Mechanism of gastroesophageal reflux in recumbent asymptomatic human subjects. J Clin Invest. 1980;65:256-267.

19. Johnson LF, Demeester TR. Twenty-four-hour pH monitoring of the distal esophagus. A quantitative measure of gastroesophageal reflux. Am J Gastroenterol. 1974;62:325-332.

20. Orr WC, Johnson LF, Robinson MG. Effect of sleep on swallowing, esophageal peristalsis, and acid clearance. Gastroenterology. 1984;86: 814-819.

21. Dickman R, Green C, Fass SS, et al. Relationships between sleep quality and $\mathrm{pH}$ monitoring findings in persons with gastroesophageal reflux disease. J Clin Sleep Med. 2007;3:505-513.

22. Moore JG. Circadian dynamics of gastric acid secretion and pharmacodynamics of $\mathrm{H} 2$ receptor blockade. Ann N Y Acad Sci. 1991;618:150-158.

23. Rogers MJ, Holmfield JH, Primrose JN, Gledhill T, Johnston D. A prospective comparison of the effects of placebo, ranitidine and highly selective vagotomy on $24 \mathrm{~h}$ ambulatory intragastric $\mathrm{pH}$ in patients with duodenal ulcer. Br J Surg. 1988;75:961-965.

24. Stacher G, Presslich B, Starker H. Gastric acid secretion and sleep stages during natural night sleep. Gastroenterology. 1975;68:1449-1455.

25. Watanabe M, Nakazawa S, Yoshino J, et al. [A study of the relationship between nocturnal intragastric $\mathrm{pH}$ and sleep stages of peptic ulcer]. Nippon Shokakibyo Gakkai Zasshi. 1995;92:1241-1249. Japanese.

26. Schubert ML, Peura DA. Control of gastric acid secretion in health and disease. Gastroenterology. 2008;134:1842-1860.

27. Okudaira K, Furuta T, Shirai N, Sugimoto M, Miura S. Concomitant dosing of famotidine with a triple therapy increases the cure rates of Helicobacter pylori infections in patients with the homozygous extensive metabolizer genotype of CYP2C19. Aliment Pharmacol Ther. 2005;21:491-497.

28. Fukuchi T, Ashida F, Yamashita H, et al. Influence of cure of Helicobacter pylori infection on gastric acidity and gastroesophageal reflux: study by $24-\mathrm{h} \mathrm{pH}$ monitoring in patients with gastric or duodenal ulcer. J Gastroenterol. 2005;40:350-360.

29. Johns CE, Newton JL, Westley BR, May FE. The diurnal rhythm of the cytoprotective human trefoil protein TFF2 is reduced by factors associated with gastric mucosal damage: ageing, Helicobacter pylori infection, and sleep deprivation. Am J Gastroenterol. 2005;100: 1491-1497.
30. Brzozowski T, Zwirska-Korczala K, Konturek PC, et al. Role of circadian rhythm and endogenous melatonin in pathogenesis of acute gastric bleeding erosions induced by stress. J Physiol Pharmacol. 2007; 58 Suppl 6:53-64.

31. Ozturk H, Oztürk H, Yagmur Y, Uzunlar AK. Effects of melatonin administration on intestinal adaptive response after massive bowel resection in rats. Dig Dis Sci. 2006;51:333-337.

32. Orr WC, Chen CL. Sleep and the gastrointestinal tract. Neurol Clin. 2005;23:1007-1024.

33. Elsenbruch S, Orr WC, Harnish MJ, Chen JD. Disruption of normal gastric myoelectric functioning by sleep. Sleep. 1999;22:453-458.

34. Orr WC, Crowell MD, Lin B, Harnish MJ, Chen JD. Sleep and gastric function in irritable bowel syndrome: derailing the brain-gut axis. Gut. 1997;41:390-393.

35. Goo RH, Moore JG, Greenberg E, Alazraki NP. Circadian variation in gastric emptying of meals in humans. Gastroenterology. 1987;93: $515-518$.

36. Soffer EE, Adrian TE, Launspach J, Zimmerman B. Meal-induced secretion of gastrointestinal regulatory peptides is not affected by sleep. Neurogastroenterol Motil. 1997;9:7-12.

37. Kumar D, Soffer EE, Wingate DL, Britto J, Das-Gupta A, Mridha K. Modulation of the duration of human postprandial motor activity by sleep. Am J Physiol. 1989;256:G851-G855.

38. Gill RC, Kellow JE, Wingate DL. Gastro-oesophageal reflux and the migrating motor complex. Gut. 1987;28:929-934.

39. Aytuğ N, Giral A, Imeryüz N, et al. Gender influence on jejunal migrating motor complex. Am J Physiol Gastrointest Liver Physiol. 2001;280:G255-G263.

40. Charles F, Evans DF, Castillo FD, Wingate DL. Daytime ingestion of alcohol alters nighttime jejunal motility in man. Dig Dis Sci. 1994;39:51-58.

41. Keller J, Gröger G, Cherian L, Günther B, Layer P. Circadian coupling between pancreatic secretion and intestinal motility in humans. Am J Physiol Gastrointest Liver Physiol. 2001;280:G273-G278.

42. Balakrishnan A, Tavakkolizadeh A, Rhoads DB. Circadian clock genes and implications for intestinal nutrient uptake. J Nutr Biochem. 2012;23:417-422.

43. Rohman SM, Emoto N, Nonaka H, et al. Circadian clock genes directly regulate expression of the $\mathrm{Na}(+) / \mathrm{H}(+)$ exchanger NHE3 in the kidney. Kidney Int. 2005;67:1410-1419.

44. Saito H, Terada T, Shimakura J, Katsura T, Inui K. Regulatory mechanism governing the diurnal rhythm of intestinal $\mathrm{H}+$ /peptide cotransporter 1 (PEPT1). Am J Physiol Gastrointest Liver Physiol. 2008;295: G395-G402.

45. Pan X, Terada T, Okuda M, Inui K. Altered diurnal rhythm of intestinal peptide transporter by fasting and its effects on the pharmacokinetics of ceftibuten. J Pharmacol Exp Ther. 2003;307:626-632.

46. Qandeel HG, Alonso F, Hernandez DJ, et al. Role of vagal innervation in diurnal rhythm of intestinal peptide transporter 1 (PEPT1). J Gastrointest Surg. 2009;13:1976-1985.

47. Tavakkolizadeh A, Berger UV, Shen KR, et al. Diurnal rhythmicity in intestinal SGLT-1 function, V(max), and mRNA expression topography. Am J Physiol Gastrointest Liver Physiol. 2001;280:G209-G215.

48. Pan X, Hussain MM. Clock is important for food and circadian regulation of macronutrient absorption in mice. J Lipid Res. 2009;50: $1800-1813$.

49. Shukla P, Gupta D, Bisht SS, et al. Circadian variation in radiationinduced intestinal mucositis in patients with cervical carcinoma. Cancer. 2010;116:2031-2035.

50. Wells M, Roth L, McWilliam M, Thompson K, Chande N. A cross-sectional study of the association between overnight call and irritable bowel syndrome in medical students. Can J Gastroenterol. 2012;26:281-284.

51. Cassone VM, Stephan FK. Central and peripheral regulation of feeding and nutrition by the mammalian circadian clock: implications for nutrition during manned space flight. Nutrition. 2002;18: $814-819$. 
52. Froy O. The relationship between nutrition and circadian rhythms in mammals. Front Neuroendocrinol. 2007;28:61-71.

53. Bassotti G, Iantorno G, Fiorella S, Bustos-Fernandez L, Bilder CR. Motility in man: features in normal subjects and in patients with chronic idiopathic constipation. Am J Gastroenterol. 1999;94:1760-1770.

54. Soffer EE, Scalabrini P, Wingate DL. Prolonged ambulant monitoring of human colonic motility. Am J Physiol. 1989;257:G601-G606.

55. Furukawa Y, Cook IJ, Panagopoulos V, McEvoy RD, Sharp DJ, Simula M. Relationship between sleep patterns and human colonic motor patterns. Gastroenterology. 1994;107:1372-1381.

56. Bassotti G, Bucaneve G, Betti C, Morelli A. Sudden awakening from sleep: effects on proximal and distal colonic contractile activity in man. Eur J Gastroenterol Hepatol. 1990;2:475-478.

57. Roarty TP, Suratt PM, Hellmann P, McCallum RW. Colonic motor activity in women during sleep. Sleep. 1998;21:285-288.

58. Rao SS, Welcher K. Periodic rectal motor activity: the intrinsic colonic gatekeeper? Am J Gastroenterol. 1996;91:890-897.

59. Rønholt C, Rasmussen OO, Christiansen J. Ambulatory manometric recording of anorectal activity. Dis Colon Rectum. 1999;42: $1551-1559$.

60. Kumar D, Waldron D, Williams NS, Browning C, Hutton MR, Wingate DL. Prolonged anorectal manometry and external anal sphincter electromyography in ambulant human subjects. Dig Dis Sci. 1990;35:641-648.

61. Ferrara A, Pemberton JH, Levin KE, Hanson RB. Relationship between anal canal tone and rectal motor activity. Dis Colon Rectum. 1993;36:337-342.

62. Ringel Y, Sperber AD, Drossman DA. Irritable bowel syndrome. Annu Rev Med. 2001;52:319-338.

63. Drossman DA, Camilleri M, Mayer EA, Whitehead WE. AGA technical review on irritable bowel syndrome. Gastroenterology. 2002;123:2108-2131.

64. Thompson JJ, Elsenbruch S, Harnish MJ, Orr WC. Autonomic functioning during REM sleep differentiates IBS symptom subgroups. Am J Gastroenterol. 2002;97:3147-3153.

65. Jarrett ME, Burr RL, Cain KC, Rothermel JD, Landis CA, Heitkemper MM. Autonomic nervous system function during sleep among women with irritable bowel syndrome. Dig Dis Sci. 2008;53: 694-703.

66. Robert JJ, Elsenbruch S, Orr WC. Sleep-related autonomic disturbances in symptom subgroups of women with irritable bowel syndrome. Dig Dis Sci. 2006;51:2121-2127.

67. Kim HI, Jung SA, Choi JY, et al. Impact of shiftwork on irritable bowel syndrome and functional dyspepsia. J Korean Med Sci. 2013;28:431-437.

68. Kellow JE, Gill RC, Wingate DL. Prolonged ambulant recordings of small bowel motility demonstrate abnormalities in the irritable bowel syndrome. Gastroenterology. 1990;98:1208-1218.

69. Nojkov B, Rubenstein JH, Chey WD, Hoogerwerf WA. The impact of rotating shift work on the prevalence of irritable bowel syndrome in nurses. Am J Gastroenterol. 2010;105:842-847.

70. Enck P, Kaiser C, Felber M, et al. Circadian variation of rectal sensitivity and gastrointestinal peptides in healthy volunteers. Neurogastroenterol Motil. 2009;21:52-58.

71. Radwan P, Skrzydlo-Radomanska B, Radwan-Kwiatek K, Burak-Czapiuk B, Strzemecka J. Is melatonin involved in the irritable bowel syndrome? J Physiol Pharmacol. 2009;60:67-70.

72. Stepień A, Moskwa-Fortuna A, Wisniewska-Jarosińska M, Harasiuk A, Chojnacki J. [Melatonin secretion and metabolism in patients with irritable bowel syndrome]. Pol Merkur Lekarski. 2009;26:440-443. Polish.

73. Mozaffari S, Rahimi R, Abdollahi M. Implications of melatonin therapy in irritable bowel syndrome: a systematic review. Curr Pharm Des. 2010;16;3646-3655.

74. Megdal SP, Kroenke CH, Laden F, Pukkala E, Schernhammer ES. Nightwork and breast cancer risk: a systematic review and metaanalysis. Eur J Cancer. 2005;41:2023-2032.
75. Stevens RG. Light-at-night, circadian disruption and breast cancer: assessment of existing evidence. Int J Epidemiol. 2009;38: 963-970.

76. Tynes T, Hannevik M, Andersen A, Vistnes AI, Haldorsen T. Incidence of breast cancer in Norwegian female radio and telegraph operators. Cancer Causes Control. 1996;7:197-204.

77. Schwartzbaum J, Ahlbom A, Feychting M. Cohort study of cancer risk among male and female shift workers. Scand J Work Environ Health. 2007;33:336-343.

78. Kloog I, Haim A, Stevens RG, Portnov BA. Global codistribution of light at night (LAN) and cancers of prostate, colon, and lung in men. Chronobiol Int. 2009;26:108-125.

79. Farriol M, Venereo Y, Orta X, Castellanos JM, Segovia-Silvestre T. In vitro effects of melatonin on cell proliferation in a colon adenocarcinoma line. J Appl Toxicol. 2000;20:21-24.

80. Anisimov VN, Popovich IG, Zabezhinski MA. Melatonin and colon carcinogenesis: I. Inhibitory effect of melatonin on development of intestinal tumors induced by 1,2-dimethylhydrazine in rats. Carcinogenesis. 1997;18:1549-1553.

81. Anisimov VN, Kvetnoy IM, Chumakova NK, et al. Melatonin and colon carcinogenesis. II. Intestinal melatonin-containing cells and serum melatonin level in rats with 1,2-dimethylhydrazine-induced colon tumors. Exp Toxicol Pathol. 1999;51:47-52.

82. Anisimov VN, Popovich IG, Shtylik AV, et al. Melatonin and colon carcinogenesis. III. Effect of melatonin on proliferative activity and apoptosis in colon mucosa and colon tumors induced by 1,2-dimethylhydrazine in rats. Exp Toxicol Pathol. 2000;52:71-76.

83. Soták M, Polidarová L, Ergang P, Sumová A, Pácha J. An association between clock genes and clock-controlled cell cycle genes in murine colorectal tumors. Int J Cancer. 2013;132:1032-1041.

84. Sahar S, Sassone-Corsi P. Metabolism and cancer: the circadian clock connection. Nat Rev Cancer. 2009;9:886-896.

85. Firestein R, Blander G, Michan S, et al. The SIRT1 deacetylase suppresses intestinal tumorigenesis and colon cancer growth. PLoS One. 2008;3:e2020.

86. Liao C, Li J, Bin Q, Cao Y, Gao F. Chronomodulated chemotherapy versus conventional chemotherapy for advanced colorectal cancer: a meta-analysis of five randomized controlled trials. Int $J$ Colorectal Dis. 2010;25:343-350.

87. Mormont MC, Waterhouse J, Bleuzen P, et al. Marked 24-h rest/activity rhythms are associated with better quality of life, better response, and longer survival in patients with metastatic colorectal cancer and good performance status. Clin Cancer Res. 2000;6:3038-3045.

88. Swanson GR, Burgess HJ, Keshavarzian A. Sleep disturbances and inflammatory bowel disease: a potential trigger for disease flare? Expert Rev Clin Immunol. 2011;7:29-36.

89. Ranjbaran Z, Keefer L, Farhadi A, Stepanski E, Sedghi S, Keshavarzian A. Impact of sleep distubances in inflammatory bowel disease. J Gastroenterol Hepatol. 2007;22:1748-1753.

90. Everson CA. Sustained sleep deprivation impairs host defense. Am J Physiol. 1993;265:R1148-R1154.

91. Redwine L, Hauger RL, Gillin JC, Irwin M. Effects of sleep and sleep deprivation on interleukin-6, growth hormone, cortisol, and melatonin levels in humans. $J$ Clin Endocrinol Metab. 2000;85: $3597-3603$.

92. Shearer WT, Reuben JM, Mullington JM, et al. Soluble TNF-alpha receptor 1 and IL-6 plasma levels in humans subjected to the sleep deprivation model of spaceflight. J Allergy Clin Immunol. 2001;107: $165-170$.

93. Tang Y, Preuss F, Turek FW, Jakate S, Keshavarzian A. Sleep deprivation worsens inflammation and delays recovery in a mouse model of colitis. Sleep Med. 2009;10:597-603.

94. Lange T, Dimitrov S, Born J. Effects of sleep and circadian rhythm on the human immune system. Ann NY Acad Sci. 2010;1193:48-59.

95. Castanon-Cervantes O, Wu M, Ehlen JC, et al. Dysregulation of inflammatory responses by chronic circadian disruption. J Immunol. 2010;185:5796-5805. 
96. Bubenik GA. Thirty four years since the discovery of gastrointestinal melatonin. J Physiol Pharmacol. 2008;59 Suppl 2:33-51.

97. Thor PJ, Krolczyk G, Gil K, Zurowski D, Nowak L. Melatonin and serotonin effects on gastrointestinal motility. J Physiol Pharmacol. 2007;58 Suppl 6:97-103.

98. Terry PD, Villinger F, Bubenik GA, Sitaraman SV. Melatonin and ulcerative colitis: evidence, biological mechanisms, and future research. Inflamm Bowel Dis. 2009;15:134-140.

99. Li JH, Yu JP, Yu HG, et al. Melatonin reduces inflammatory injury through inhibiting NF- $\mathrm{\kappa B}$ activation in rats with colitis. Mediators Inflamm. 2005;4:185-193.
100. Mei Q, Yu JP, Xu JM, Wei W, Xiang L, Yue L. Melatonin reduces colon immunological injury in rats by regulating activity of macrophages. Acta Pharmacol Sin. 2002;23:882-886.

101. Jan J, Freeman R. Re: Mann - melatonin for ulcerative colitis? Am J Gastroenterol. 2003;98:1446.

102. Talero E, García-Mauriño S, Motilva V. Melatonin, autophagy and intestinal bowel disease. Curr Pharm Des. Epub November 18, 2013.

\section{Publish your work in this journal}

ChronoPhysiology and Therapy is an international, peer-reviewed, open access journal focusing on research into the cyclic variations and rhythmicity in physiological processes in the body and the research and development and optimal timing of administration of therapeutic targets to achieve improved outcomes and quality of life for the patient. The
Dovepress

manuscript management system is completely online and includes a very quick and fair peer-review system. Visit http://www.dovepress.com/ testimonials.php to read real quotes from published authors.

\footnotetext{
Submit your manuscript here: http://www.dovepress.com/chronophysiology-and-therapy-journal
} 